\title{
Confidentiality: the confusion continues
}

\author{
D J Kenny North West Thames Regional Health Authority
}

\section{Editor's note}

The author, a regional health authority administrator, argues that 'ownership' is a side issue in legal and moral arguments over confidentiality of medical records. Nor is it practicable, he argues, for doctors alone to control all access to the medical records. He proposes the principle of 'custodianship' of confidential information, to be accepted by an institution as a whole, as a possible way of resolving the problem. In commentaries on this and the following article an academic lawyer and a practising physician respond.

\section{Introduction}

A sharply worded Lancet leader (I) described the Child Health Computing Committee argument as 'a factless debate' and regretted the failure by the parties to raise the level of discussion. But a successful debate requires clarity over the main issues or at the very minimum some precision in vocabulary and these prerequisites have been absent from much of the confidentiality debate for some time: even the otherwise admirable Lancet leader employed the terms 'confidentiality' and 'privacy' as though they were synonymous. This paper examines two remarkably durable sources of confusion, ownership of the medical record and definition of 'a third party'.

\section{Ownership of the medical record}

It is commonly assumed - and often stated - that among the rights exercisable by the owner of the record is a right under certain circumstances to release confidential information from it. It has also been assumed that by invoking the concept of ownership of either the record or the information contained in it one could thereby construct a legal mechanism for a patient to protect his privacy. Neither assumption is correct.

If a 'right' is to be of any tangible value it must in some way be capable of being protected. It seems that it was with this in mind that many European and American commentators in the late 1960 s and early I970s tended to assume that a patient's rights could be protected through the 'ownership' of the medical record and, by extension, control of the information which that record contained. Certainly privacy could be secured in the practical sense that the family doctor or the hospital which owned the document had de facto control of its use. In no sense, however, does that confer any rights on the patient and nor does it in any legal sense help him to obtain redress.

Eventually this approach was dropped, but not before several absorbing debates had occurred on ownership of the information in the record which has been supplied to the doctor by the patient. Is the information entered in the record by the doctor and not supplied by the patient (eg diagnosis) owned only by the doctor? Further, if a radiologist in private practice supplies a report to a surgeon, also in private practice what are the respective ownership rights of the radiologist, surgeon and patient over that information?

This is all very interesting but somewhat beside the point as no Western legal system recognises ownership of information as a separate legal concept, distinct from the ownership of the document containing it. (Copyright law is a totally separate issue.)

Although the Lindop Committee (2) got it right (3) and no one 'owns' the information in the medical record, the Health Service Commissioner (4) and now the Minister for Health (5) have inadvertently obscured the issue again by referring to ownership of the record in terms that could imply that it gave rights over the information and could influence the rights of the patient.

The fact is that ownership of the record is totally irrelevant to the patient's rights for privacy. Until there is privacy legislation in the United Kingdom patients will continue to depend for protection of their rights solely on the behaviour standards of the professional bodies and individuals involved in their care and it obscures the issue dangerously to imply anything else.

\section{The 'third party' issue}

Confidentiality is breached if information obtained during consultation or treatment is transmitted to 'a third party' without the patient's consent. Modern medicine legitimately involves a great many people in the patient's treatment and other social institutions may have a direct or indirect involvement in some aspect of his care. It is important therefore to be clear about which people have 
legitimate access to patient information as part of their work and which people - third parties - cannot receive such information without the prior consent of the patient.

Three statements merit consideration:

I) 'A doctor shall preserve absolute secrecy on all he knows about his patient because of the confidence entrusted in him'. This extract from the International Code of Medical Ethics implies that a breach of confidentiality will occur if information obtained through professional consultation is passed on by anyone to a third party without the consent of his patient.

2) During discussions with the British Association of Social Workers (BASW) the British Medical Association (BMA) defined a 'third party' as 'anyone not in a direct professional relationship with the doctor'.

3) The Central Ethical Committee of the BMA have also stated (6) as a principle that:

Access to identifiable information held in medical records is to be confined to the author and to the person clinically responsible for the patient during the episode for which the data has been collected (or their successors) unless specifically authorised by the clinician in the clinical interest of the patient.

It appears from this that the BMA's line is that the way to resolve the patient's lack of legal rights is to place the onus for control upon the doctor. But the matter is not as simple as that and such an approach does not solve all the problems. This self-imposed onus contains two serious flaws, one ethical and the other practical.

The ethical flaw occurs because the doctor, in the context of the BMA/BASW and the Child Health Computing debates is suddenly put in the position of determining on his own judgment what patient information should be passed and to whom. In the majority of cases this can work; it would be done in the best interests of patient care and would probably be accepted by the patient. Yet it does not properly take into account the precise nature of the 'contract' between doctor and patient, namely that the basis of the confidential relationship is that the patient gives the doctor information in circumstances where the patient can fully comprehend the extent to which that information will be imparted to others in the health team for his own clinical care. Patients in general are fairly well-informed on this.

If, however, at a later date some other person appears on the scene who could not be said to have been within the contemplation of the patient when he imparted information during his treatment (a research worker or a social agency representative, for example), this is a new situation and one in which the patient should have the opportunity to 'agree' the onward transmission of the data. It

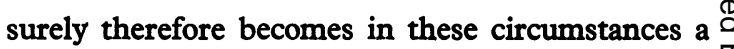
matter for the patient and not the doctor to say whether the information may be passed on. The BMA approach appears to leave that decision solely with the doctor.

Not only is that BMA position suspect on purely ethical grounds - there is a second flaw and that is the sheer impossibility for the doctor of being able $\bar{\omega}$ to 'deliver'. Modern health care requires direct $\vec{\partial}$ involvement of a widening circle (7) of professional, $\frac{a}{0}$ technical and ancillary staff. Patient data are $\infty$ generated in a great many locations in a hospital and $\overrightarrow{0}$ handled by a wide range of different parties. These $\overrightarrow{-}$ staff cannot all be in a 'direct professional relation- $\vec{\omega}$ ship' with the doctor and it would be wholly un- $\overrightarrow{3}$ realistic to hold a doctor responsible for controlling $\overparen{\nabla}$ their work; that is the clear responsibility of the health institution and its officers. Yet this con- 0 sideration did not prevent the BMA in a circular 0 letter (8) to Members of Parliament criticising the Child Health Computing Scheme because sensitive $>$ patient data was being controlled by '... administrators ... responsible to superior administrators, not $\stackrel{\Im}{\Im}$ to the patients whose medical confidence they hold'.

\section{Discussion}

It is important to reduce the amount of confusion in this discussion particularly if the prospect of government action becomes slightly greater. One concept explored recently (9) may offer a device for unlocking the problem. That is the concept of custodianship.

In essence, custodianship signifies that range of responsibilities in relation to the custody of confidential information which is imposed upon and accepted by a (health care) institution as a whole. It is a general duty imposed upon all who work in an institution no matter what professional codes govern their actions and no matter upon what basis they handle records or data, whether they generate, manipulate, transmit or simply store that data. The standard of confidentiality to be achieved within that institution would be agreed by the institution in consultation with medical and on occasions other $N$ professional interests, but the overall responsibility for ensuring that that standard was maintained would fall to the institution.

This would involve in effect the establishment of an institutional code of practice and it would be 0

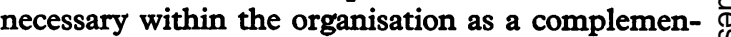
tary exercise to the setting of standards, to working out safe procedures and clearly assigning respective roles and responsibilities.

This approach would have the advantage of making it unnecessary in the absence of privacy $\stackrel{\square}{\Omega}$ legislation to base respective rights and duties on considerations of where the information is held and 8 whether the person who holds it is its originator, keeper, user or owner. It would have the additional 
advantage of making it easier to demonstrate openly a proper standard of confidentiality rather than laying responsibility artificially on a particular member of the organisation which is the difficulty created if one follows the logic of the BMA line.

It would not deal entirely with the problem of identifying a third party who works outside the institution, but could make it easier to regulate transmission of information to any external body. Once such a mechanism were established it would be easier to see how some of the more difficult third party issues might be tackled. It is not the aim of this paper to discuss the conflict between confidentiality and issues of wider public interest, but if one accepts the Kennedy (10) argument that many decisions made by doctors require consideration of social values on which they may need guidance, or Thompson's view (II) that there are so many exceptions that the principle of confidentiality is in danger of being eroded out of existence, then custodianship may at least provide a mechanism for dealing with such issues. For example the decision as to whether or not information about a patient should be released to the police would not be made arbitrarily by either the consultant or the administrator. Instead it would have to be decided in the context of the institution's custodianship procedures.

How would such a system be set up ? At health authority level an integrated strategy could be worked out which simultaneously ensured that:

a) professional staff set and review standards of confidentiality to be achieved in given situations, and b) the health authority accepted its responsibilities for maintaining that standard.

The setting of standards requires medical commitment and multi-disciplinary consideration with doctors, nurses and computer experts, and might be assisted by the establishment of a small standing committee, rather like an ethical committee to which problems could be referred and which could if necessary take the initiative itself to take up problems.

The health authority for its part could agree and make public its policies for data protection such as recognition of the need for informed consent of patients to the release of information and clauses in staff contracts which set out their obligations in relation to the handling of patient information. It does this already in other fields and as Health and Safety and Equal Opportunities legislation.

This might at least ensure that future discussions take place within a comprehensible and publicly scrutinised framework.

\section{References}

(I) Confidentiality of medical records - a factless debate. Lancet 1980 Dec 6: 1230.

(2) Report of the Committee on Data Protection (Lindop Report). Cmnd. 7341. London: HMSO, 1978.

(3) See reference (2). Paras 7.11, 18.07.

(4) Annual Report of the Health Service Commissioner 1979-80. London: HMSO, 1980: Chap 5; para $86: 33$.

(5) DHSS Circular (80) I4. Confidentiality of medical records. London: DHSS, 1980.

(6) BMA Central Ethical Committee. Three ethical principles. London: British Medical Association, 1980.

(7) Data protection in health information systems: Considerations and guidelines. North Holland, 1980: II.

(8) Letter from British Medical Association to Members of Parliament, 1978 August 31.

(9) See reference (7) p 22.

(I0) Kennedy I. The Reith Lectures: Unmasking medicine. The Listener 1980 Nov 6, 13, 20, 27, Dec 4, II.

(II) Thompson I E. The nature of confidentiality. fournal of medical ethics $1979 ; 2$ : 57-64.

\section{Continued from page 4}

\section{References}

(I) The Declaration of Helsinki 1964, revised 1975. Reprinted (under 'Declarations') In: Duncan A S, Dunstan G R, Welbourn R B, eds. Dictionary of Medical Ethics. London: Darton, Longman and Todd, r98r.

(2) The Nuremberg Code, 1947. See Dictionary of Medical Ethics, as in reference (I).

(3) Medical Research Council. Annual Report 1962-63. London: HMSO, 1963; Cmd 2382: $21-25$.

(4) Royal College of Physicians. Supervision of the ethics of clinical research investigations in institutions. London, 1973.

(5) DHSS. Supervision of the ethics of clinical research investigations and fetal research. London, 1975; HSC(IS)I53.

(6) Godber Sir G. Constraints on the advance of medicine. Proceedings of the Royal Society of Medicine. 1974; 67: 13II.

(7) BMA. The Handbook of Medical Ethics. London, 1980, revised r981.

(8) British Paediatrics Association. Guidelines to aid ethical committees considering research involving children. Archives of Disease in Childhood 1980; 55: 75-77.

(9) Schwartz A H. Children's concepts of research hospitalisation. New England fournal of Medicine 1972; 287: 589-592.

(10) Campbell A G M. Infants, children and informed consent. British Medical fournal r974; 3: 334-338. 